\title{
La gestión organizativa del Sistema Nacional de Salud
}

\section{Alfonso Florez Díaz}

Arbor CLXX, 670 (Octubre 2001), 309-315 pp.

Plantea el autor la importancia de desarrollar culturas organizativas en las instituciones que emanen de la propia reflexión interna, con un convencimiento y por lo tanto con un compromiso e implicación que consiga no sólo sensibilizar a la organización de la necesidad de mejora continua, sino que además logren enraizarse y asentarse en la misma como algo sólido que los profesionales lo asuman como beneficioso para su labor dentro de la organización, horizontalizando su estructura y aumentando su funcionalidad.

\section{Introducción}

En todo el territorio, de la Sanidad Pública española (tanto en el entorno INSALUD como en las Comunidades transferidas), la gestión organizativa está ampliamente enriquecida de experiencias aisladas con la puesta en marcha de instrumentos de gestión, que en unos casos abarcan a toda la organización, los menos, y otros en los que solamente están involucrados profesionales con iniciativa propia, que desarrollan y/o desarrollaron estos instrumentos. En algunos casos perduran, por haberlos puesto en marcha con la participación de un colectivo significativo, por la existencia de un líder o por el apoyo de la Administración. En otros desaparecen por la inexistencia de estas condiciones, la falta de continuidad en los proyectos, la aceleración indebida 
para la obtención de resultados rápidos, y en definitiva por la carencia de expertos en metodología organizacional.

En la actualidad no existe ningún modelo sanitario que satisfaga de forma general a la población, en la órbita de los Estados modernos; y se contempla casi como una utopía, el conseguir unos estándares de satisfacción donde la población asistida y los profesionales coincidan de forma plena.

La necesidad de renovar la Organización de los Servicios Sanitarios Públicos, proviene de la misma dinámica de la evolución social, que recoge de forma amplia la Ley General de Sanidad. Todo ello ha implicado, en estas últimas dos décadas, una importante dotación presupuestaria que aunque quizás no suficiente, ha supuesto la creación de nuevos centros, contratación de personal, incorporación de nuevas tecnologías,...etc., para lo cual este Servicio Público en la práctica no estará, ni está preparado, lo cual complica más su optimización organizacional.

El desafío técnico y práctico está en diseñar modelos integrales de DESARROLLO ORGANIZACIONAL, a la medida de la demanda de nuestra sociedad asistida y sociolaboral, en la confianza de ir alcanzando secuencialmente, éxitos que satisfagan a sus protagonistas, los PACIENTES, y PROFESIONALES DEL SISTEMA PÚBLICO DE SALUD, en el ánimo de ir alcanzando una operativa de equipos, de organización equilibrada en función de que PACIENTE-MEDICO tengan la capacidad plena del derecho a decidir, en la confianza de una organización que va a responder y a respetar esas decisiones.

\section{Consideraciones Generales}

Las organizaciones tienen vitalidad en tanto y en cuanto se autoincentivan para crear, para incorporar novedades desde los equipos y desde las personas que las componen. Es evidente que la pericia de sus gestores para saber coordinar estas iniciativas, tutelarlas y llevarlas al éxito, está en el hilo conductor de propiciar la formalización de lo positivo. De este modo, desde las estructuras más formales, se debería premiar y reforzar a aquellos profesionales y equipos que trabajan a niveles informales con el reconocimiento que supone incorporar novedades a la cadena de valor. Los gestores tienen que tener la capacidad de valorar aquellas iniciativas que siendo positivas, son factibles, y de propiciar el reconocimiento al esfuerzo de aquellos profesionales cuyas propuestas aún no teniendo la maduración o el rigor suficiente 


\section{La gestión organizativa del Sistema Nacional de Salud}

merecen que se les proporcione el marco que facilite su evolución. En resumen «afianzar lo positivo y positivizar lo negativo».

Desde esta perspectiva debe considerarse el futuro que se hace proyectando hacia delante, y de la historia, del pasado, se aprende para no cometer los mismos errores. De ese pasado es necesario obtener hechos concluyentes de observación y de estudio para la ponderación de sus resultados.

De las experiencias habidas, y de forma muy general, se puede decir que ha habido demasiados cambios que «VIENEN DESDE ARRIBA», y que muchos de ellos, la mayoría, fueron de marcado carácter aparentemente estructural y económico. Lo cual no quiere decir que no hallan sido un aprendizaje importante, de conocimiento de cuánto cuesta lo que se hace; y a partir de la limitación del gasto, dentro del ámbito de lo moral, no sería más conveniente dedicarlo a otra alternativa más rentable para los tratamientos de los pacientes. Conjuntamente con lo económico, el sistema binario empezó a volcar datos que las organizaciones no han podido digerir a causa de que faltan otros aspectos muy importantes, intrínsecos a un servicio sanitario, la participación en el fundamento de la Misión inmediata de cada uno de los miembros en la organización. Y en ello se han perdido oportunidades importantes, de las que han salido frustraciones personales, de equipos y de organización, con un fuerte componente de resistencia a cualquier cambio.

Este resultado, permítase la expresión, de «emboscamiento», es producto de haber perdido excesivas oportunidades del «cambio organizativo» que han sido pilotadas sin los acompañamientos de metodología suficiente, contrasta con la capacidad científica de aprendizaje del sector sanitario, que evoluciona de forma vertiginosa en el conocimiento que se obtiene desde la investigación de la ingeniería genética, de la informática aplicada, de la farmacología... etc., donde el colectivo sanitario, directa o indirectamente, participa en esa evolución científica y tan positiva para la salud, que en periodos de tiempo muy cortos le resta importancia por su uso inmediato o por la aparición de otro hallazgo más importante. Lo cual nos indica de forma paradigmática que son organizaciones en un continuo aprendizaje, frente al mimetismo en la innovación y la mejora organizativa.

En el rango de conclusiones sería equívoco el efectuar comparaciones, pero es importante como paradigma de confrontación, no solamente en la generalidad de lo expuesto, sino en lo que ello significa diariamente, en el entorno con el paciente, en las instalaciones arquitectónicas, en los desajustes de tiempos de organización,... etc. 


\section{Tendencias actuales en las necesidades de organización}

Sabido es que una Empresa que se precie es la que proyecta su futuro, la que genera ideas de mejora continua.

Es necesario conectar metodología que no sea dispersa, que sea lo más homologada posible, y en la que esté inserta la participación de los componentes.

Así mismo se hace necesario el dar valor formal a lo intangible; el paradigma de la numeración, tiene que ser racionalizado y efectuar la ponderación imprescindible para valorar la sabiduría. El conocimiento de las organizaciones, y en concreto el contenido de los Servicios de la Sanidad Pública, es demasiado importante para que no se formalice.

Sin duda la tarea es minuciosa, pero hay que involucrar en ella a todos los profesionales, no sólo médicos, sino a todos los estamentos.

La tendencia actual, -que no las modas-, está en la horizontalización de las organizaciones, en su capacidad de informar fielmente, de dar cuanta información se necesite, pero veraz. Y en ello se incluye cual es la misión de la Empresa, de los equipos y de cada uno de los miembros de la organización. De lo anterior se desprende que los mandos intermedios están prácticamente en la operativa diaria. Es decir tender a que exista la menor distancia entre la dirección y la función operativa, (como máximo tres niveles de coordinación).

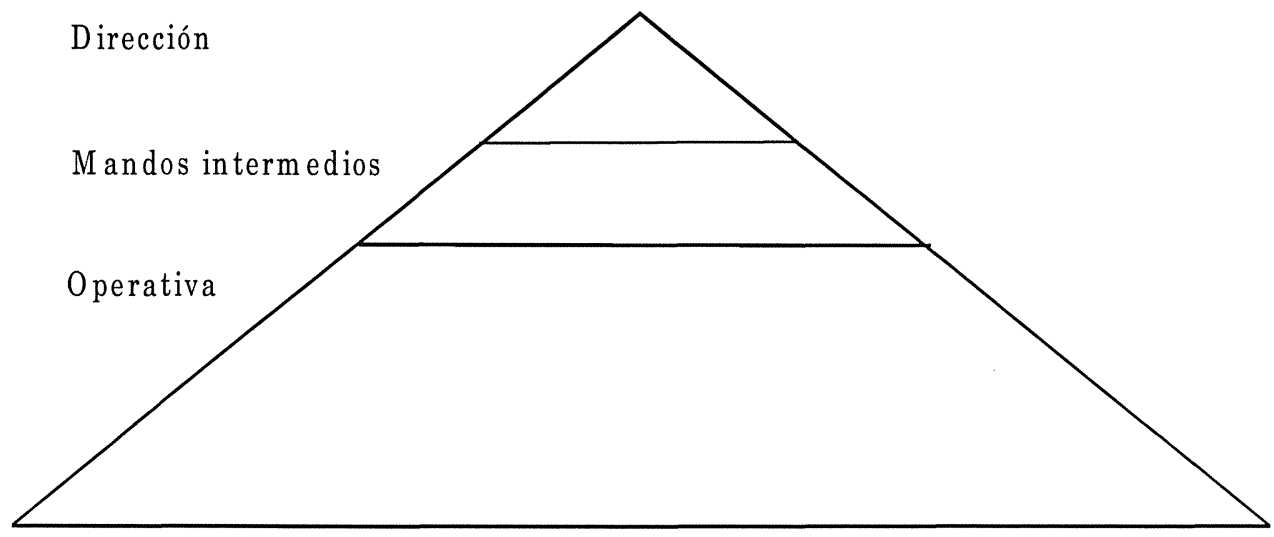

Ello genera organizaciones transversales, que trabajan teniendo en cuenta los agentes colaterales.

En el servicio sanitario, la población asistida debe constituir la razón fundamental de su quehacer, no como pretexto sino con el convencimiento de que una adecuada definición de funciones y procesos, centrados en el paciente, será clave para la prestación de un buen servicio. 


\section{La gestión organizativa del Sistema Nacional de Salud}

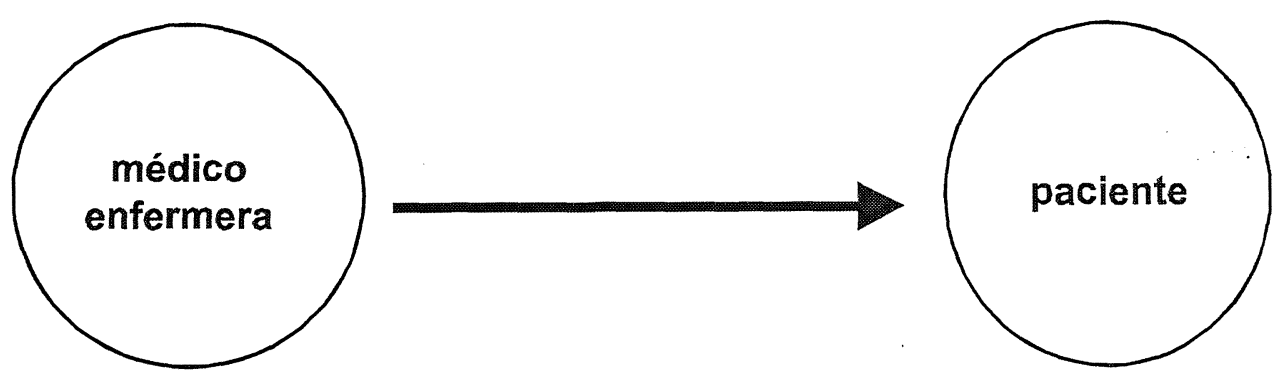

Para ello el análisis tiene que ser efectuado desde el paciente y sus interlocutores inmediatos, Médicos y Enfermería. Es evidente que la distancia más corta es la línea recta de interrelación y las demás funciones de la organización tiene el cometido de velar para que esta línea recta no tenga ningún bucle es decir, «El Todo» en torno a este eje:

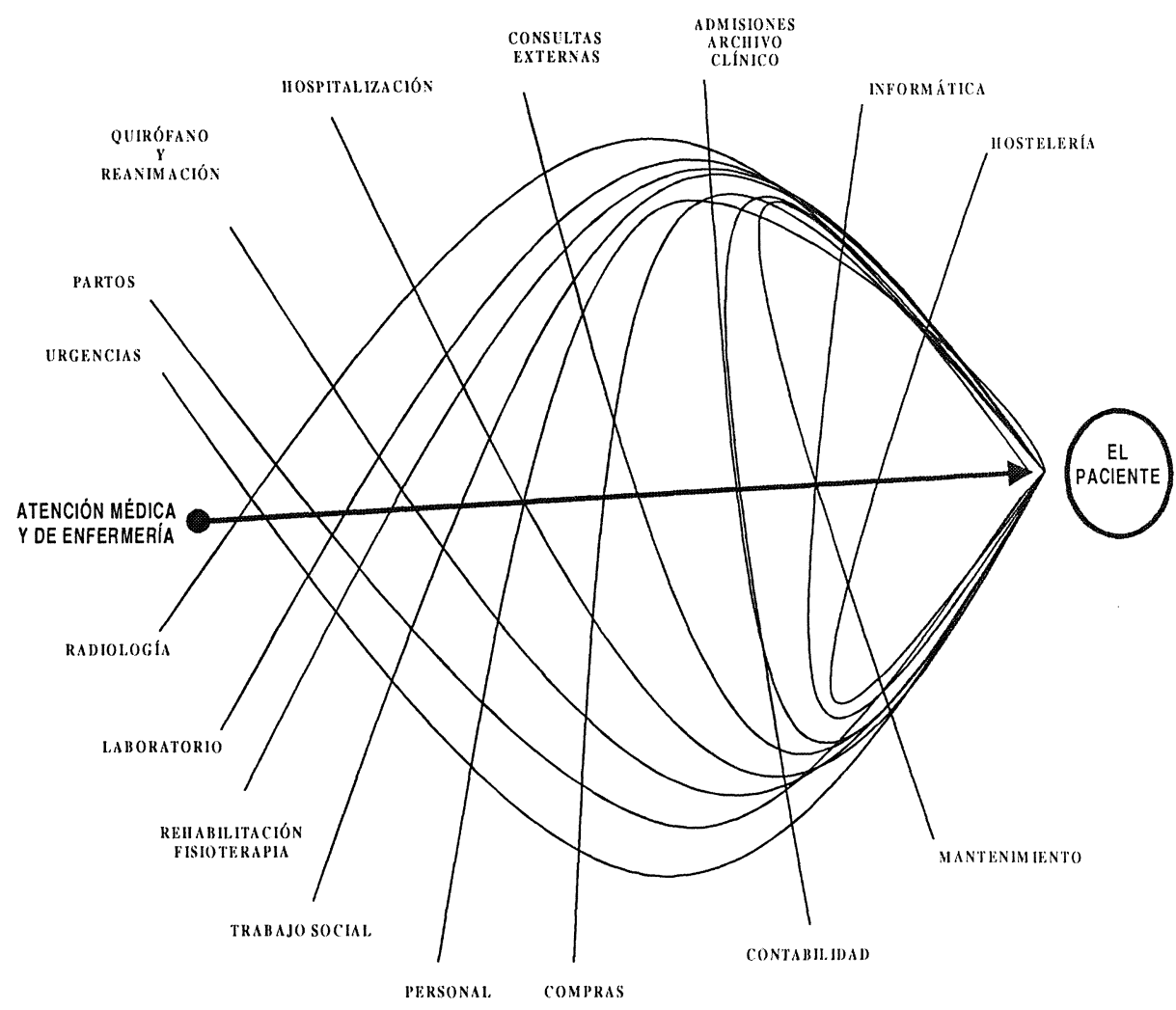


En esta organización compleja todo interviene en todo, y todos los cruces de las líneas de función tienen su correlación. Para lo cual es imprescindible concebir personas que sean coordinadores y responsables de línea. De tal forma que el eje central se encontrará protegido, envuelto, por la organización: Especialistas diagnósticos, de farmacia, de tratamientos, hostelería, compras, departamentos de personal, archivos, etc.

Este tipo de organización, (tiende al objetivo «0 Fallos»), persigue la coordinación de la calidad, el determinar las funciones de referencia de líneas de actuación, dar responsabilidades profesionales y objetivos concretos claros y conocidos, implicando una descentralización de la toma de decisiones y coordinando la gestión.

Como instrumentos de gestión de carácter general, son varios los que coadyuvan a esta puesta en común (Técnicas cliente-proveedor, Vías Clínicas, Unidades funcionales, etc...), pero todas ellas tienen que abarcar al conjunto de la organización para resolver el problema de todos. No es aconsejable la creación de «islotes de gestión»; siempre han creado problemas de agravios comparativos entre profesionales y equipos, de estas disfunciones lo que se obtiene es el agravio del Paciente.

Esta propuesta de organización tiene un único equilibrio en su capacidad de sincronizarse y de adaptación para cada paciente en un entorno donde el objetivo final de la calidad asistencial está en «el inmediato». Una vez alcanzado esto, habremos conseguido los objetivos intermedios que estructuran la organización. Finalmente reseñar que problemas como la carrera profesional, política retributiva, etc. están implícitos en el desarrollo de este esquema de organización.

\section{Bibliografía}

1 Coleman D. Liderazgo que consigue resultados. Harvard Business Review. Abril 2.000 .

2 Plan estratégico. Libro azul. Instituto Nacional de la Salud. 1997.

3 Fundación Alternativas. El futuro de la sanidad española. Un proyecto de reforma. Exlibis Ediciones. 1999.

4 La financiación de los Servicios Regionales de Salud. Problemas y probables soluciones. Gaceta sanitaria. 1991.

5 ColangE S., Rodriguez M. Consecuencias distributivas y de equidad de las políticas de gasto y financiación de la sanidad.. Papeles de economía, 1998

6 SÁnchez Bayle M. Crisis de la medicina y de la profesión médica en España. Madrid, enero de 1994-abril de 1995.

7 Palma M., LÁzARo P. y otros Una exploración de la dedicación de los médicos en su organización.

8 LuCAS MARín, A. Sociología para la empresa. Madrid 1994. 


\section{La gestión organizativa del Sistema Nacional de Salud}

9 MuÑoz LóPez. Management en el tercer milenio. Madrid 1997.

10 GoRE, E. Aprendiendo en contextos organizativos. La educación en la empresa. Barcelona 1996.

11 VILlLAFAÑE, J. Imagen positiva. Gestión estratégica de la imagen de las empresas. Madrid 1993.

$12 \mathrm{M}^{\circ}$ A.P. Dirección pública: gestión y legitimidad. Laufer/burlaud. Madrid. 1987.

13 Perez-IÑigo, C. y Moro, I. Calidad total en los servicios públicos y en la empresa. Ministerio para las Administraciones Públicas. Madrid. 1992.

14 Crozier, M. El fenómeno burocrático. (2 vol.) Buenos Aires. 1974.

15 RoDRIGUEz LóPEZ, J.L.. Viejos valores y nuevas burocracias. El caso de una empresa semipública. $\mathrm{M}^{\mathbf{0}}$ de Trabajo y Seguridad Social. Madrid. 1989.

16 SubIRATs, J. Análisis de políticas públicas y eficacia de la administración. Instituto Nacional Admon. Pública. Madrid. 1989.

\section{Sobre nuevas concepciones de la organización:}

17 El big bang de las organizaciones. Serie yx Herve. Ediciones B. Barcelona. 1994.

18 Hammer, M. y CHAMPY. Reingeniería de la empresa. Parramón. Barcelona. 1994.

19 MoRgan, G. Images of organization. SAGE. Londres. 1986.

20 SENGE, P.M. La quinta disciplina. El arte la práctica de la organización abierta al aprendizaje. Granica. Barcelona, 1992.

21 Peters, T. Del caos a la excelencia... Folio. Barcelona. 1990. 